\title{
PENYEBARAN KARAT DAUN Olivea tectonae (UREDINALES) PADA Tectona grandis DI JAWA DAN SUMATERA
}

\author{
Distribution of Leaf Rust Olivea tectonae (Uredinales) on Tectona grandis in \\ Java and Sumatera \\ Luciasih Agustini ${ }^{1)}$, Dyah Manohara ${ }^{2)}$ dan/and Dono Wahyuno ${ }^{2)}$ \\ ${ }^{1)}$ Pusat Penelitian dan Pengembangan Hutan dan Konservasi $\mathrm{Ala}^{\mathrm{m}}$ \\ Jl. Gunung Batu No. 5, PO Box 165, Bogor, Telp. (0251) 8633234, Fax. (0251) 8633111 \\ ${ }^{2)}$ Balai Penelitian Tanaman Obat dan Aromatik \\ J1. Tentara Pelajar No. 3, Cimanggu, Bogor 16111, Telp. (0251) 832187, Fax. (0251) 8327010
}

Naskah masuk : 30 April 2008; Naskah diterima : 16 April 2009

\begin{abstract}
Teak (Tectona grandis) is an important timber tree and is widely distributed in Indonesia. Leaves samples collected from various areas in Java and Sumatera shown infected by rust fungus. The objectives of the study were to identify the fungus and determine its geographic distribution in West Indonesia. Identification was carried out by observing morphological characteristics and measuring the size of uredinia, urediniospore, and paraphysis under light microscope. The results indicated that the teak leaf rust is Olivea tectonae. The detected life cycle stage was uredinia only, while the other stages were not present. The fungus was observed from all samples collected from four provinces, i.e., Central Java, East Java, West Java and Lampung.
\end{abstract}

Key words: Olivea tectonae, Tectona grandis, rust

\begin{abstract}
ABSTRAK
Jati (Tectona grandis) merupakan tanaman hutan yang mempunyai nilai komersial tinggi, sehingga jati dibudidayakan di banyak tempat di Indonesia. Beberapa contoh daun jati yang dikumpulkan dari berbagai lokasi di Pulau Jawa dan Sumatera menunjukkan gejala terserang cendawan karat. Kegiatan ini bertujuan mengidentifikasi cendawan karat dan memetakan penyebarannya. Identifikasi dilakukan dengan mengamati struktur morfologi cendawan, menentukan stadianya dan mengukur karakteristik morfologinya, antara lain: uredinia, urediniospora, dan paraphysis di bawah mikroskop cahaya. Hasil identifikasi menunjukkan Olivea tectonae sebagai cendawan karat penyebabnya bercak daun jati. Stadia yang didapat adalah uredinia, sedang stadia lainnya tidak ditemukan. O. tectonae ditemukan dari semua contoh daun yang diamati yang dikumpulkan dari empat provinsi, yaitu: Jawa Barat, Jawa Tengah, Jawa Timur dan Lampung.
\end{abstract}

Kata kunci: Olivea tectonae, Tectona grandis, cendawan karat

\section{PENDAHULUAN}

Jati (Tectona grandis L. f) merupakan tanaman hutan yang telah dibudidayakan di Indonesia, khususnya di Pulau Jawa, untuk diambil kayunya sebagai bahan mebeler atau bahan bangunan. Tanaman ini tersebar dari semenanjung India, hingga ke Burma, Thailand, Philipina dan Indonesia (Phengklai et al. 1994). Sampai saat ini dilaporkan ada tiga spesies dari genus Tectona, yaitu Tectona hamiltonia Wall ex Schau, T. phillippinensis Benth \& Hook f dan T. grandis. Di antara tiga spesies tersebut, $T$. grandis 
merupakan jenis yang paling banyak ditemukan, sedang T. phillippinensis sebarannya terbatas di Filipina (Phengklai et al., 1994). Di Jawa dilaporkan ada dua spesies yaitu T. grandis dan T. hamiltonia, tetapi $T$. hamiltonia baru dalam tahap uji coba penanaman di Banyumas (Backer dan Van Den Brink, 1965).

Jati merupakan tanaman yang dapat tumbuh pada kisaran ekosistem yang luas, dari dataran rendah hingga dataran tinggi $( \pm 600 \mathrm{~m} \mathrm{dpl})$, dalam bentuk hamparan maupun terpisah-pisah yang tumbuh dengan tanaman lainnya, tetapi jati sangat dominan dalam berkompetisi, sehingga tidak mudah mengalami erosi genetik (Phengklai et al., 1994). Tanaman ini dapat tumbuh di daerah kering maupun basah. Di daerah kering, jati akan menggugurkan daunnya selama musim kemarau, dan sebaliknya di daerah yang airnya cukup jati akan berdaun sepanjang tahun (Backer dan Van Den Brink, 1965).

Phengklai et al. (1994) melaporkan adanya satu jenis cendawan yang menyerang jati, yaitu Corticium salmonicolor B \& Br. Di Indonesia, selain C. salmonicolor, ada pula Diplodia, Helicobasidium, Rigidoporus dan Ustulina pernah dilaporkan menyerang tanaman jati (Semangun, 1992); serta Olivea (Boedjin, 1960) dan Cercospora (Boedjin, 1962).

Berdasarkan beberapa material yang telah dikumpulkan dari berbagai lokasi di Pulau Jawa dan Sumatera, semua contoh daun yang diambil menunjukkan adanya gejala nekrosa yang menyebar, yang dalam kondisi tertentu meluas hingga 10-20\% dari luas daun. Pada bagian bawah daun menunjukkan adanya debu warna kuning yang mengindikasikan serangan cendawan karat. Gejala tersebut ditemukan di semua tanaman jati yang pernah dikunjungi, bahkan debu warna kuning tersebut ditemukan hampir menutup seluruh permukaan daun khususnya yang ada di bagian bawah. Kegiatan ini bertujuan untuk mengidentifikasi cendawan penyebab karat dari material yang telah dikumpulkan dan memetakan penyebarannya.

\section{BAHAN DAN METODE}

Materi berupa daun jati yang menunjukkan gejala nekrosa dan adanya debu warna kuning dikumpulkan dari berbagai lokasi perkebunan rakyat yang dikunjungi. Contoh tanaman disimpan dalam bentuk awetan kering (herbarium), dan disimpan sebagai koleksi di Balai Penelitian Tanaman Obat dan Aromatika (Balittro) Bogor. Spesimen yang diamati berupa spesimen kering (herbarium) yaitu: HBI-Bal (Herbarium Bogor Indonesia-Balittro) 277 Majalengka, Jawa Barat, September 6, 2004; HBI-Bal 364 Liwa, Lampung, Juli 26, 2005; HBI-Bal 368 Cimanggu, Bogor, Jawa Barat, Agustus 2, 2005; HBI-Bal 376 Somagede, Banyumas, Jawa Tengah, Mei 3, 2006; HBI-Bal 385 Sempiuh, Banyumas, Jawa Tengah, Mei 2, 2006; HBI-Bal 388 Somagede, Banyumas, Jawa Tengah, Mei 3, 2006; HBI-Bal 394 Bulukerto, Wonogiri, Jawa Tengah, Mei 6, 2006; HBI-Bal 395 Bulukerto, Wonogiri, Jawa Tengah, Mei 6, 2006; HBIBal 403 Disbun Kendal, Kendal, Jawa Tengah, Mei 9, 2006; HBI-Bal 408 Takeran, Magetan, Jawa Timur, July 15, 2006; HBI-Bal 409 Boyolali, Jawa Tengah, Juli 16, 2006 ; HBI-Bal 415 Cahaya Negeri, Lampung Utara, Lampung, Agustus 14, 2006; dan HBI-Bal 417 Pakuwon, Parung Kuda, Sukabumi, Jawa Barat, Maret 2, 2007.

Pengamatan dilakukan dengan melakukan sayatan melintang pada bagian yang terdapat tubuh buah cendawan dengan menggunakan pemotong yang tipis dan tajam (Streets, 1972); atau mengambil bagian tanaman yang mengandung cendawan dan meletakkannya di dalam larutan laktophenol di gelas preparat untuk diamati dan diukur (Wahyuno, 2001). Pengamatan struktur morfologi dilakukan di bawah mikroskop cahaya, dan pengukuran karakteristik morfologi yang ada dilakukan menggunakan mikrometer yang terdapat di lensa okuler. Setiap parameter diukur kisaran panjang, lebar dan rata-ratanya berdasarkan dari 30 contoh pengamatan.

Pengukuran yang dilakukan terhadap spora dan paraphysis meliputi parameter: panjang, lebar, ketebalan dinding sel. Paramater lainnya yang diamati adalah bentuk spora, paraphysis, jumlah lubang kecambah dan penyebarannya. Stadia cendawan karat yang ditemukan, dinamakan berdasar sistem ontogeni yang diusulkan oleh Cummins dan Hiratsuka (1983), yaitu berdasarkan fungsi dari stadia tersebut. 


\section{HASIL DAN PEMBAHASAN}

Jati merupakan tanaman yang dalam pertumbuhannya relatif tidak banyak mendapat gangguan dari mikroorganisme pengganggu, meskipun beberapa cendawan dan bakteri pernah dilaporkan ditemukan pada tanaman ini. Hal ini mungkin karena selama ini tanaman jati banyak dibudidayakan di daerah kering dataran rendah, dimana pada saat musim kemarau siklus hidup dari mikroorganisme patogen yang menyerang daun akan terputus atau menurun populasinya bersamaan dengan berkurangnya daun jati akibat digugurkan. Seiring dengan kecenderungan masyarakat yang membutuhkan tanaman yang mempunyai kayu berkualitas, tanaman ini sudah banyak dibudidayakan di dataran yang relatif basah. Untuk itu, antisipasi akan munculnya cendawan yang berpotensi mengganggu pertumbuhannya perlu dilakukan.

Pengamatan yang telah dilakukan terhadap contoh daun bergejala nekrosa dengan warna kuning di sekitarnya menunjukkan adanya serangan cendawan karat. Pada pengamatan detail, cendawan karat tersebut membentuk uredinia pada permukaan bawah daun. Uredinia banyak terbentuk di sekitar ketiak tulang daun, sedang uredinosporanya yang terlepas banyak yang masih menempel pada permukaan bawah daun yang umumnya mempunyai rambut yang lebat, sehingga terlihat warna kuning yang memudar pada bagian bawah daun yang terserang (Gambar 1a dan 1b). Pada stadia yang lanjut di bagian tempat uredinia tumbuh menjadi nekrosa yang luasannya kadang terbatas oleh tulang daun, sehingga, nekrosa yang terbentuk berbentuk persegi, atau membentuk luasan berwarna coklat yang tidak teratur.

Secara mikroskopis, uredinia berbentuk mangkuk dan tumbuh pada lapisan epidermis permukaan bawah daun (hypophyllous) dengan paraphysis di sekelilingnya, dan urediniospore dengan ukuran yang bervariasi terdapat di dalamnya (Gambar 1c dan Tabel 1). Urediniospora berbentuk bulat sampai lonjong, permukaannya berduri (echinulate), berwarna kuning terang, berukuran 16,3 - 30,0 x 15,0 - 22,0 $\mu \mathrm{m}$, tebal dindingnya berkisar antara $0,8-2,5 \mu \mathrm{m}$, dan lubang perkecambahannya (germ-pore) umumnya tidak jelas, berjumlah 2-4 dan tersebar ditengah (equatorial) (Gambar 1d). Bagian tepi uredinia dikelilingi oleh parafisis yang berbentuk gada (clavate), melengkung (curve), berukuran 20,0 - 30,0 x 45,0 - 57,5 $\mu \mathrm{m}$, mempunyai ketebalannya berkisar antara 0,3 - 3,8 $\mu \mathrm{m}$, dan tidak berwarna (hyaline) (Gambar 1e). Stadia uredinia (II) ditemukan dari 13 contoh sampel yang diamati. Bentuk teliospore (III) tidak ditemukan, demikian juga dengan bentuk spermatia (0), dan aecia(I).

Tabel (Table) 1. Rata-rata dengan standar deviasi dari karakteristik morfologi urediniospore dan parafisis $O$. tectonae (The mean with standard deviation of morphological characteristics of urediniospore and paraphysis of $\mathrm{O}$. tectonae)

\begin{tabular}{|c|c|c|c|c|c|c|c|}
\hline \multirow{2}{*}{ No } & \multirow{2}{*}{$\begin{array}{l}\text { Kode } \\
\text { (Code) }\end{array}$} & \multirow{2}{*}{$\begin{array}{c}\text { Lokasi } \\
\text { (Geographic locality) }\end{array}$} & \multirow{2}{*}{$\begin{array}{l}\text { Stadia } \\
\text { (Stage) }\end{array}$} & \multicolumn{2}{|c|}{ Urediniospora } & \multicolumn{2}{|c|}{ Parafisis } \\
\hline & & & & $\begin{array}{c}\text { Panjang }(\mu \mathrm{m}) \\
(\text { Length })\end{array}$ & $\begin{array}{c}\text { Lebar }(\mu \mathrm{m}) \\
(\text { Width })\end{array}$ & $\begin{array}{c}\text { Panjang }(\mu \mathrm{m}) \\
(\text { Length) }\end{array}$ & $\begin{array}{c}\text { Lebar }(\mu \mathrm{m}) \\
(\text { Width })\end{array}$ \\
\hline 1 & HBI-Bal 277 & Majalengka, Jawa Barat & II & $21,6 \pm 1,6$ & $19,0 \pm 1,3$ & $35,2 \pm 7,1$ & $8,9 \pm 1,4$ \\
\hline 2 & HBI-Bal 364 & Liwa, Lampung & II & $24,2 \pm 2,0$ & $20,1 \pm 0,9$ & $43,9 \pm 8,3$ & $10,7 \pm 2,8$ \\
\hline 3 & HBI-Bal 368 & Bogor, Jawa Barat & II & $22,6 \pm 1,1$ & $18,6 \pm 1,5$ & $39,4 \pm 11,7$ & $10,0 \pm 1,5$ \\
\hline 4 & HBI-Bal 376 & Banyumas, Jawa Tengah & II & $22,9 \pm 1,8$ & $19,0 \pm 1,5$ & $36,6 \pm 5,4$ & $9,1 \pm 1,6$ \\
\hline 5 & HBI-Bal 385 & Banyumas, Jawa Tengah & II & $22,6 \pm 1,5$ & $19,3 \pm 1,2$ & $35,0 \pm 5,3$ & $9,7 \pm 1,0$ \\
\hline 6 & HBI-Bal 388 & Banyumas, Jawa Tengah & II & $23,4 \pm 1,7$ & $18,5 \pm 1,2$ & $39,9 \pm 7,2$ & $11,0 \pm 1,8$ \\
\hline 7 & HBI-Bal 394 & Wonogiri, Jawa Tengah & II & $22,8 \pm 2,0$ & $19,7 \pm 1,1$ & $36,0 \pm 9,2$ & $7,9 \pm 1,0$ \\
\hline 8 & HBI-Bal 395 & Wonogiri, Jawa Tengah & II & $20,7 \pm 2,0$ & $17,3 \pm 1,5$ & $39,0 \pm 5,6$ & $10,0 \pm 1,9$ \\
\hline 9 & HBI-Bal 403 & Kendal, Jawa Tengah & II & $22,9 \pm 2,3$ & $19,0 \pm 1,0$ & $38,6 \pm 5,8$ & $9,3 \pm 1,3$ \\
\hline 10 & HBI-Bal 408 & Magetan, Jawa Timur & II & $22,3 \pm 1,9$ & $18,4 \pm 1,2$ & $36,8 \pm 5,9$ & $9,3 \pm 1,3$ \\
\hline 11 & HBI-Bal 409 & Boyolali, Jawa Tengah & II & $21,7 \pm 1,4$ & $18,7 \pm 1,1$ & $36,3 \pm 6,4$ & $9,3 \pm 1,1$ \\
\hline 12 & HBI-Bal 415 & Cahaya Negeri, Lampung & II & $21,6 \pm 1,1$ & $18,3 \pm 1,6$ & $36,8 \pm 7,3$ & $10,5 \pm 1,5$ \\
\hline 13 & HBI-Bal 417 & Sukabumi, Jawa Barat & II & $23,3 \pm 1,7$ & $18,1 \pm 1,3$ & $42,9 \pm 8,2$ & $10,4 \pm 1,2$ \\
\hline
\end{tabular}

Keterangan : ( ) nilai rata-rata dengan standardeviasi. ( ) mean with its standard deviation. 
Berdasarkan pada karakteristik morfologi tersebut di atas, cendawan karat pada jati termasuk Olivea (Uredinales: Chaconiaceae) seperti yang dideskripsikan oleh Ono (1983); dan spesiesnya adalah Olivea tectonae, Ured (T.S. Ramakrishnan \& Ramakrishnan) Mulder and Gibson. Keberadaan cendawan karat di jati di Indonesia pernah dilaporkan oleh Raciborski (1900), mendapatkannya di Bogor dan Purworejo, dan mengidentifikasinya sebagai Uredo tectonae. Boedjin (1960) melakukan revisi dan menyebutkan bahwa karat pada jati sebagai O. tectonae (Rac.) Thirumalachar.

Dari tiga belas sampel, hanya stadia uredinia yang ditemukan selama pengamatan, dan tidak ditemukan stadia lainnya. Kobayashi et al. (1988) hanya mendapatkan stadia uredinia yang ditemukan pada tanaman jati di Filipina, meskipun beberapa diantaranya diambil dari daerah dekat dengan pegunungan. Demikian juga, Arguedas (2004) mendapatkan uredinia O. tectonae di Panama dan Costarica; dengan urediniospore berukuran 20 - 26 x $15-20 \mu \mathrm{m}$, dan parafisis $40-70 \times 10-20 \mu \mathrm{m}$. Di Australia, juga hanya stadia uredinia dengan urediniospore berukuran $18-26 \times 16-21 \mu \mathrm{m}$, dan parafisis $30-45 \times 10-17 \mu \mathrm{m}$ (Daly et al., 2006). O. tectonae diduga mempunyai siklus hidup macro cyclic autoecious, yaitu mempunyai siklus hidup yang lengkap dan tidak memerlukan inang alternatif untuk melewati stadia spermogonia (0) dan aecia (I), tetapi sampai saat ini yang pernah dilaporkan keberadaannya hanya stadia uredinianya (Ono dan Hennen, 1983). Dari tujuh spesies Olivea yang diketahui, hanya dua spesies yang telah diketahui siklus hidupnya secara lengkap, sedang lima spesies lainnya termasuk $O$. tectonae baru uredinia dan teliosporenya saja yang diketahui (Ono, 1984).

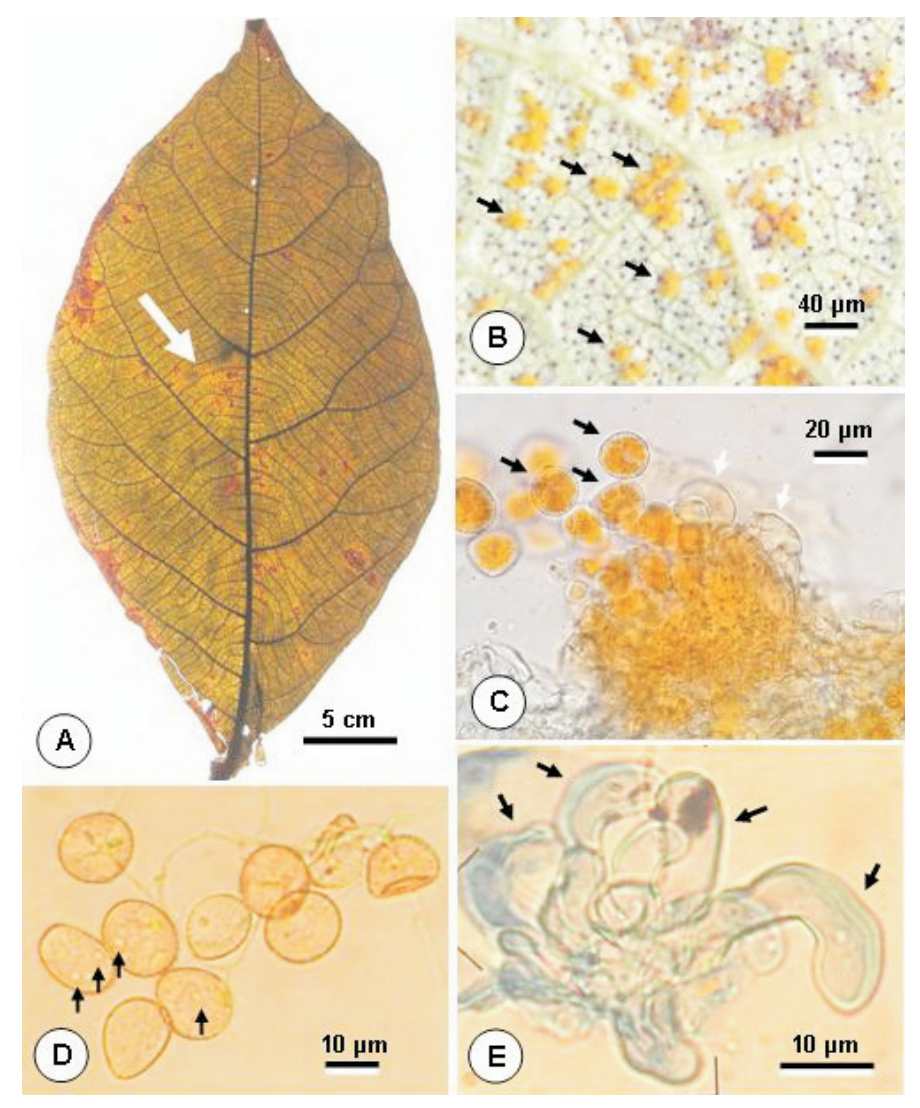

Gambar(Figure) 1. Olivea tectona pada jati (HBI-Bal 364). (A) Bagian daun jati yang terserang (panah) Olivea, (B) Uredinia yang terbentuk pada permukaan bawah daun (panah), (C) Urediniospora (panah hitam) dikelilingi parafisis (panah putih), (D) Urediniospora dengan lubang kecambahnya (panah) dan (E) Parafisis. (Olivea tectonae on teak (HBI-Bal 364). (A) Infected parts of teak leaf by Olivea (arrow), (B) Uredinia formed on lower leaf surface, (C) Urediniospores (black arrow) surrounded by paraphysis (white arrow), (D) Urediniospores with its germpore (arrow) and (E) Paraphysis. 
Seiring dengan perluasan tanaman jati, yang telah tersebar tidak hanya di daerah beragroekosistem kering di Jawa, seperti Jawa Timur dan sebagian Jawa Tengah saja tetapi telah sampai di sebagian Jawa Barat dan Sumatera, khususnya Lampung. Nampaknya $O$. tectonae telah beradaptasi dengan baik bersamaan dengan daya adaptasi dari tanaman inangnya, yang mempunyai kisaran agroekosistem sangat luas dari dataran tinggi Liwa di Lampung hingga dataran rendah Kendal di Jawa Tengah (Gambar 2). Chaconia, Chrysocelis, Goplana, dan Olivea merupakan genera yang banyak terdapat di daerah tropis (Ono, 1984). Selain Indonesia, O. tectonae telah tersebar di India, Thailand, Sri Lanka, Pakistan, Burma, dan Taiwán (Ono dan Hennen, 1983), Filipina (Ono dan Hennen, 1983; Kobayashi dan Guzman, 1988), Australia (Daly et al., 2006) dan Costa Rica (Arguedas, 2004).

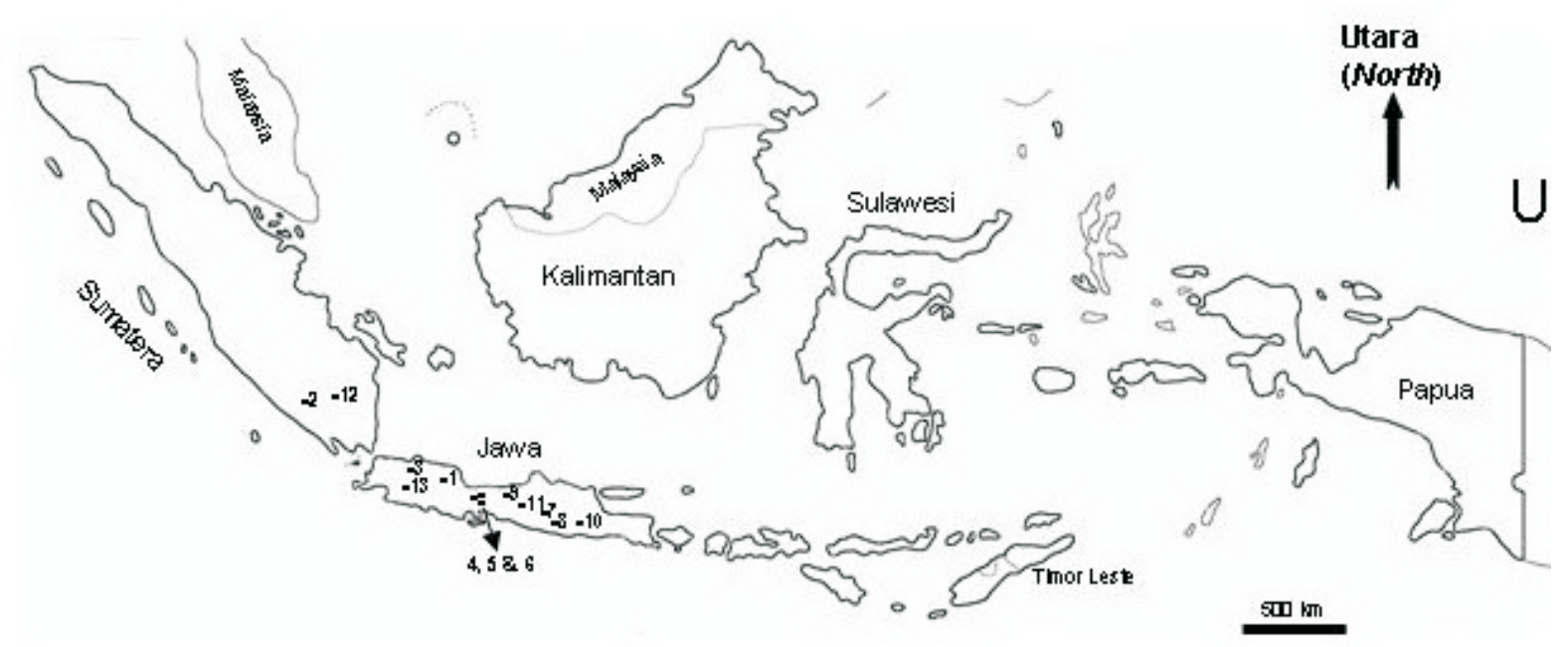

Gambar(Figure) 2. Sebaran O. tectonae di Indonesia. Angka yang tertera di dalam peta sesuai dengan keterangan lokasi yang terdapat pada Tabel 1. (Distribution of O. tectonae in Indonesia. Numbers appear in map are correspond with those mentioned in Table 1).

Walaupun $O$. tectonae bersifat parasit obligat, tetapi karena di beberapa tempat tanaman jati tidak harus menggugurkan semua daunnya, maka $O$. tectonae dapat dipastikan akan mudah ditemukan sepanjang tahun di daerah yang beriklim basah. Di Bogor, gejala serangan karat dapat dijumpai pada daun yang letaknya $10 \mathrm{~cm}$ hingga lebih dari $5 \mathrm{~m}$ di atas permukaan tanah, dan dapat ditemukan sepanjang tahun. Bagaimana $O$. tectonae bertahan pada daerah yang daunnya gugur semua belum pernah dilakukan pengamatan, meskipun urediniospora diketahui memiliki dinding tebal dan relatif mampu bertahan pada kondisi kering lebih lama dibanding spora cendawan lainnya. Puccinia triticina L. pada gandum mampu mempertahankan kelangsungan hidupnya selama musim dingin dalam bentuk miselia dormansi, sori yang bersporualasi pada jaringan yang telah mati, atau urediniospore yang bertahan di dalam uredinia (Eversmeyer dan Kramer, 2000).

Penelitian yang berkaitan dengan aspek eko-biologi cendawan karat yang berasal dari tropis masih sangat terbatas. Sampai saat ini, kerugian yang disebabkan oleh $O$. tectonae belum pernah dianalisa. Dengan semakin luasnya penyebaran $O$. tectonae, beragamnya jenis jati yang dibudidayakan dan banyak ditemukan $O$. tectonae pada tanaman yang masih muda, maka penelitian ke arah variasi patogenisitas maupun teknologi pengendaliannya harus mulai dipertimbangkan.

\section{KESIMPULAN}

Olivea tectonae penyebab karat pada tanaman jati di Indonesia. Hanya stadia uredinia yang ditemukan, baik di daerah dataran rendah maupun tinggi di Jawa dan Sumatera. 


\section{DAFTAR PUSTAKA}

Arguedas, M. 2004. La roya de la teca Olivea tectonae (Rac): consideraciones sobre su presenia en Panamá y Costa Rica. Kurú, Revista Forestal 1:1-6 (with english summary)

Backer, C.A. dan R.C.B.Z. Van Den Brink. 1965. Flora of Java (Spermatophytes only) II. N.V.P. Noordhoff-Groningen, The Netherlands. 601-602 pp.

Boedjin, K.B. 1960. Uredinales of Indonesia. Nova Hedwigia I (34): 463-494

Boedjin, K.B. 1962. The genus Cercospora in Indonesia. Nova Hedwigia 3: 411-438

Cummins, G.B. and Y. Hiratsuka. 1983. Illustrated Genera of Rust Fungi. Rev. Eds. Amer. Phytopathol. Soc., St. Paul, Minnesota.

Daly, A.M., R.G. Shivas, G.S. Pegg dan A.E. Mackie. 2006. First record of teak leaf rust (Olivea tectonae) in Australia. Australian Plant Disease Note 1:25-26.

Eversmeyer, M.G. dan C.L. Kramer. 2000. Epidemiology of wheat leaf and stem rust in the Central Great Plains of the USA. Ann. Rev. Phytopathology 38: 491-513.

Kobayashi, T. dan E.D. de Guzman. 1988. Monograph of tree diseases in the Phillipines with taxonomic notes on their associated microorganisms. Bull. of the Forestry and Forest Products Res. Inst. Ibaraki, Japan 351: 99-200.

Ono, Y. 1984. Taxonomy of rust genera formerly classified in the tribe Oliveae. Rept. Tottori Mycol. Inst. Japan 22:186-190.

Ono, Y. dan J.F. Hennen. 1983. Taxonomy of the Chaconiaceous genera (Uredinales). Trans. Mycol. Soc. Japan. 24:369-402.

Phengklai, C., T. Smitinand, J. Kartasubrata, P.B. Laming, S.C. Lim dan M.S.M Sosef. 1994. Tectona. In I. Soerianegara dan R.H.M.J. Lemmens (Eds). Plant Resources of South East Asia (1) Timber Trees: Major Commercial Timbers. Prosea, Bogor. Indonesia. 448-454 pp.

Raciborski, M. 1900. Parasitische Algen und Pilze Java's. Bot. Inst. Buitenzorg, I. J Cramer.

Semangun, H. 1992. Host index of Plant Diseases in Indonesia. Gadjah Mada University Press.

Streets, R.B. 1972. Diagnosis of Plant Diseases. The University of Arizona Press.

Wahyuno, D., M. Kakishima dan Y. Ono. 2001. Morphological analyses of urediniospores and teliospores in seven Phragmidium species on ornamental roses. Mycoscience 42: 519-533. 